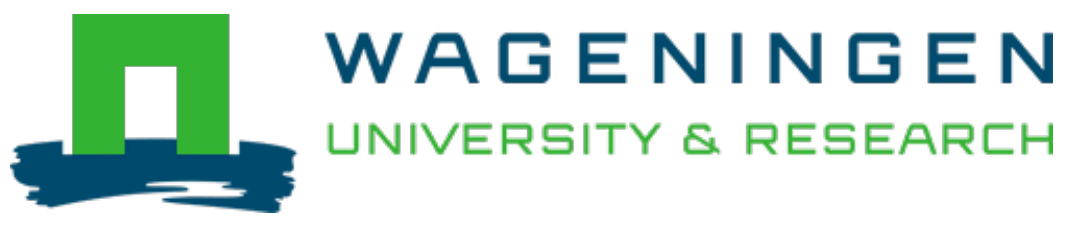

\title{
Recovery of eggplant field waste as a source of phytochemicals
}

\author{
Scientia Horticulturae \\ Mauro, Rosario Paolo; Agnello, Michele; Rizzo, Valeria; Graziani, Giulia; Fogliano, Vincenzo et al \\ https://doi.org/10.1016/j.scienta.2019.109023
}

This article is made publicly available in the institutional repository of Wageningen University and Research, under the terms of article $25 \mathrm{fa}$ of the Dutch Copyright Act, also known as the Amendment Taverne. This has been done with explicit consent by the author.

Article $25 \mathrm{fa}$ states that the author of a short scientific work funded either wholly or partially by Dutch public funds is entitled to make that work publicly available for no consideration following a reasonable period of time after the work was first published, provided that clear reference is made to the source of the first publication of the work.

This publication is distributed under The Association of Universities in the Netherlands (VSNU) 'Article $25 \mathrm{fa}$

implementation' project. In this project research outputs of researchers employed by Dutch Universities that comply with the legal requirements of Article $25 \mathrm{fa}$ of the Dutch Copyright Act are distributed online and free of cost or other barriers in institutional repositories. Research outputs are distributed six months after their first online publication in the original published version and with proper attribution to the source of the original publication.

You are permitted to download and use the publication for personal purposes. All rights remain with the author(s) and / or copyright owner(s) of this work. Any use of the publication or parts of it other than authorised under article $25 \mathrm{fa}$ of the Dutch Copyright act is prohibited. Wageningen University \& Research and the author(s) of this publication shall not be held responsible or liable for any damages resulting from your (re)use of this publication.

For questions regarding the public availability of this article please contact openscience.library@wur.nl 


\title{
Recovery of eggplant field waste as a source of phytochemicals
}

\author{
Rosario Paolo Mauro ${ }^{\mathrm{a}, *}$, Michele Agnello ${ }^{\mathrm{a}}$, Valeria Rizzo ${ }^{\mathrm{a}}$, Giulia Graziani ${ }^{\mathrm{b}}$, Vincenzo Fogliano ${ }^{\mathrm{c}}$, \\ Cherubino Leonardi ${ }^{a}$, Francesco Giuffrida ${ }^{a}$
}

${ }^{a}$ Department of Agriculture, Food and Environment, University of Catania, via Valdisavoia, 5, 95123, Catania, Italy

${ }^{\mathrm{b}}$ Department of Pharmacy, University of Napoli "Federico II", Via D. Montesano, 49, 80131, Napoli, Italy

${ }^{\mathrm{c}}$ Food Quality \& Design Group, Wageningen University, PO Box 8129, 6700 EV, Wageningen, the Netherlands

\section{A R T I C L E I N F O}

\section{Keywords:}

Solanum melongena L.

Anthocyanins

Polyphenols

Steroidal glycoalkaloids

Residual waste

\begin{abstract}
A B S T R A C T
The influence of ripening stage was evaluated on fruit characteristics of three widely cultivated eggplant cultivars (Birgah, Black Bell and Black Moon), with the aim to characterize their fruit residual waste for phytochemicals extraction. At overripening stage, eggplant fruits showed the highest average weight, dry matter content and weight incidence of the pulp. Total anthocyanins concentration of the peel (mainly represented by nasunin) was higher at commercial ripening, whereas total polyphenols (most of all 5-O-caffeoylquinic acid) and steroidal glycoalkaloids ( $\alpha$-solasonine and $\alpha$-solamargine) peaked at the overripening stage. Because of these modifications, every ton of fresh fruit gave up to $59 \mathrm{~g}$ of total anthocyanins, $1054 \mathrm{~g}$ CAE of total polyphenols and $252 \mathrm{~g}$ of total glycoalkaloids, depending on cultivar and fruit ripening stage. This study highlighted the possibility to manage the choice of cultivar and harvest time in the view of valorise this raw material for phytochemical extraction.
\end{abstract}

\section{Introduction}

The food systems encompass a sequence of steps, producing worldwide significant amounts of putrescible bio-wastes. Over time, the waste externalization at global scale has increased dramatically, following the vast rise in human population and urbanization processes (Xu et al., 2015; Ingrao et al., 2018). Nowadays bio-wastes production or underutilization are perceived as primary matter of social concern, given the economic and environmental costs associated to landfilling (Bong et al., 2017). In this context, farms represent the first step of biowaste production, in some cases generating significant losses of organic materials (unharvested or damaged fruits, other plant-derived biomasses) containing high levels of valuable bioactive compounds, so burdening the economic losses related to insufficient bio-wastes utilization (Riggi and Avola, 2008).

Over the last decades, the growing consumers' demand for natural, health-promoting products in food, cosmetics and pharmaceuticals, as well the availability of more safe and environmental-friendly extraction techniques (Lang and Wai, 2001), has lead to promote the search for natural raw materials as sources of bioactive compounds (Peschel et al., 2006). In this view, the acquisition of scientific knowledge appears of pivotal importance in the view of combining an added economic value for industrial processors and a more environmental-friendly waste management (Schieber et al., 2001).

Eggplant (Solanum melongena L.) is an important crop in many areas worldwide, with Italy being the main producer among the European counties (10,031 out of the 27,053 grown in 2016) (Faostat, 2018). In Southern Italian regions it is present both as an open field (for summerautumn productions) and greenhouse crop (mainly for off-season productions), with a partial overlapping of the product during early summer. Eggplant fruits are harvested at commercial maturity, a stage preceding the modifications of pulp quality and peel appearance induced by physiological ripening (Leonardi and Giuffrida, 2009). Over recent years, the crop has gained growing attention from both consumers and scientific community, as a noticeable source of bioactive molecules in food and for industrial processors (Azuma et al., 2008; Raigón et al., 2010). This characteristic arises from the presence of three main classes of phytochemicals, namely anthocyanins in the peel, caffeoylquinic acids and steroidal glycoalkaloids mainly in the pulp (Milner et al., 2011; Niño-Medina et al., 2017). The former two classes are well known to possess high ROS scavenging activity, playing an important role in preventing a multitude of human inflammatory and degenerative diseases, including anti-carcinogenic effects in many human cancer cells, such as leukemia and lung cancer (Friedman, 2015). Several eggplant extracts are currently available on the market, even in forms of capsules as herbal supplements, with anthocyanins

\footnotetext{
* Corresponding author.

E-mail address: rosario.mauro@unict.it (R.P. Mauro).
} 
being of interest also as natural food colouring substances (Todaro et al., 2009). Beyond their neurotoxic effects as food components (Gürbüz et al., 2018), eggplant glycoalkaloids are of paramount importance for pharmacological purposes, as they serve as precursors or lead molecules for the synthesis of steroidal drugs regulating inflammation, menopause, or used for cardiovascular therapies (Jayakumar and Murugan, 2015).

The concentration of these compounds in eggplant fruit and allied species has been demonstrated to be dependent on ripening stage (Mennella et al., 2012), but the data available concern genotypes with limited diffusion and are mainly intended for breeding purposes. As a result, a quantitative approach is still lacking in defining the exploitability of the eggplant fruit as raw material for phytochemical extraction. Indeed, because of the competitive market dynamics, significant amounts of greenhouse eggplant fruits are yearly left unharvested and, once dried up with the crop, destined to landfilling or soil incorporation. Both solutions have major drawbacks, being soil incorporation a potential source of agronomic problems too, such as retention of plant pathogens (Alkoaik and Ghaly, 2006), or interference with plant nutrition dynamics, similarly to other solanaceous crops (Riggi and Avola, 2010).

Hence, the goal of the present study was to evaluate the effects of genotype and ripening stage on carpometric and biochemical traits of greenhouse eggplant fruits produced at the end of the growing season, with the aim to provide useful information to best valorise this raw material for phytochemical extraction purposes.

\section{Materials and methods}

\subsection{Experimental site, plant material and management practices}

A greenhouse experiment was conducted over 2015-2016 growing season, at the coastal plain Southwest of Ragusa (Sicily, South Italy; $36^{\circ} 50^{\prime} \mathrm{N}, 14^{\circ} 28^{\prime} \mathrm{E}, 18 \mathrm{~m}$ a.s.l.), the most representative area for greenhouse eggplant cultivation in Italy.

The deep, sandy soil had been cultivated in solanaceous-cucurbits rotations for more than 30 years, covered with plastic mulch and used for greenhouse eggplant production for the last 6 years.

The climate of the area is semi-arid Mediterranean, with mild winters and hot, dry summers. The mean 20 year maximum summer monthly temperatures are $29.8{ }^{\circ} \mathrm{C}$ (June), $33.1{ }^{\circ} \mathrm{C}$ (July), $31.8{ }^{\circ} \mathrm{C}$ (August) and $27.6{ }^{\circ} \mathrm{C}$ (September).

Ungrafted plantlets of three $\mathrm{F}_{1}$ eggplant hybrids, namely Birgah with globose, violet fruits (Seminis, Milan, Italy), Black Bell with blackbrownish, elongated fruits and Black Moon with black, ovoid fruits (both from Monsanto, St. Louis, Missouri) were transplanted on 14 September 2015 at the stage of 2 true leaves, adopting a $0.40 \times 1.0 \mathrm{~m}$ rectangular format ( 2.5 plant $\left.\mathrm{m}^{-2}\right)$. The whole experiment was arranged in a factorial, two-way randomized blocks design (cultivar $\mathrm{x}$ ripening stage) with four replicates, using $4.0 \times 6.0 \mathrm{~m}$ experimental units. The overall experimental area inside the greenhouse was $576 \mathrm{~m}^{2}$, including 1440 plants (768, excluding border plants), divided into 24 net experimental units ( 3 cultivars $\mathrm{x} 2$ ripening stages $\mathrm{x} 4$ replicates) each containing 32 plants.

The greenhouse hosting the crop had a steel tubular structure and lateral windows along the sides, covered on late August with a $200 \mu \mathrm{m}$ thick ethylene vinyl acetate (EVA) film, with a total visible transmittance $\geq 86 \%$. All the plants were managed according to the same standard commercial practices, receiving $15.2 \mathrm{~g} \mathrm{~N}, 8.7 \mathrm{~g} \mathrm{P}_{2} \mathrm{O}_{5}, 12.8 \mathrm{~g}$ $\mathrm{K}_{2} \mathrm{O}$, $8.4 \mathrm{~g} \mathrm{MgO}$ and $0.2 \mathrm{~g}$ Fe per plant. During the crop cycle drip irrigation was provided when accumulated daily evaporation reached $25 \mathrm{~mm}$. Plants were grown until 30 June 2016, with fruit harvests occurring from 6 November 2015 up to 30 June 2016. For the analyses, only the fruits harvested on June 142016 and on June 302016 were considered.

\subsection{Fruit collection and sample preparation}

Eggplant fruits were harvested at two ripening stages, namely commercial ripening and overripening stage, from plants having a similar fruit load $\left(\sim 6 \pm 1\right.$ berries plants ${ }^{-1}$, at different developmental stages). On June 142016 (i.e. 274 days after planting), within all the 24 plots, fruits reaching the commercial ripening stage were marked. This stage was defined according to the experience of growers in the considered cultivation area. On the same date, 12 fruits per plot, diseasefree and without peduncles were harvested from as many plants within 12 out of 24 plots. On June 302016 (i.e. 290 days after planting) on the remaining 12 plots, 12 previously marked fruits were harvested from as many plants at overripening stage, i.e. when the epicarp colour of the berries turned. Soon after harvest, fruit weight and external chromatic coordinates were determined. The chromatic coordinates were measured as described by McGuire (1992) on equatorial and polar ends of the whole fruits, through a tristimulus Minolta Chroma meter (model CR-200, Minolta Corp.), and then described by lightness ( $L^{*}$ ), green-red axis $\left(a^{*}\right)$, blu-yellow axis $\left(b^{*}\right)$, Hue angle (as arctangent $\left.b^{*} / a^{*}\right)$ and Chroma [as $\left(a^{*^{2}}+b^{*^{2}}\right)^{1 / 2}$ ]. After that, fruits were peeled and the resulting components (peel and pulp) were kept separately, chopped into small pieces, lyophilized and grounded for the succeeding analytical determinations. Subsamples of the raw materials were kept in a thermoventilated oven at $70{ }^{\circ} \mathrm{C}$ (Binder, Milan, Italy) until constant weight was reached in order to determine the dry matter content for peel and pulp separately; results were then expressed on percentage basis.

\subsection{Peel anthocyanins analysis}

Peel anthocyanins were determined using the procedure reported by Ferarsa et al. (2018) with few modifications. Briefly, $1 \mathrm{~g}$ of lyophilized peel was extracted with $25 \mathrm{~mL}$ methanol containing TFA $1 \%$, and placed in ultrasonic water bath for $30 \mathrm{~min}$, then ultracentrifuged, filtered and analyzed in HPLC. Elution was performed using $1 \%$ TFA aqueous solution as phase (A) and methanol as phase (B). The gradient rate was as follows: $20-20 \% \mathrm{~B}(2 \mathrm{~min}), 20-40 \% \mathrm{~B}(10 \mathrm{~min}), 40-60 \% \mathrm{~B}$ (15 min), $60-70 \% \mathrm{~B}(20 \mathrm{~min}), 70-20 \% \mathrm{~B}(33 \mathrm{~min})$ at a constant flow of 1 $\mathrm{mL} / \mathrm{min}$. Detection was set at $520 \mathrm{~nm}$ for all samples.

The HPLC/MS/MS analyses were performed on API 3000 triple quadrupole mass spectrometer (Applied Biosystem Sciex), with a Turboionspray interface, coupled with an HPLC binary micropump (Perkin Elmer mod. series 200). All the analyses were performed using drying gas (N2) at $400{ }^{\circ} \mathrm{C}$. Chromatographic separations of anthocyanins were performed on a Luna $3 \mu \mathrm{C} 18100 \AA(50 \times 2.00 \mathrm{~mm})$ (Phenomenex) column using the following: mobile phases, water, $0.5 \%$ trifluoroacetic acid (solvent A), and methanol (solvent B). The following gradient elution was applied: 0-10 min $80 \%$ solvent A and $20 \%$ solvent B; $10-12$ min $100 \%$ solvent B; and $12-14 \operatorname{min~} 80 \%$ solvent A and $20 \%$ solvent B. Anthocyanins quantification was based on a standard curve prepared with cyanidin 3-glucoside and expressed on dry weight basis of the peel.

The MS/MS detection was performed by acquiring data in positive ion mode. The quantification was carried out in multiple reaction monitoring. Ions corresponding to $[\mathrm{M}+\mathrm{H}]^{+}$, each by specific molecular weights and fragments were monitored. In particular, were monitored ions with $m / z 611, m / z 773$ and $m / z 920$ corresponding to delphinidin3-rutinoside, delphinidin-3-rutinoside-5-glucoside and delphinidin-3coumaroylrutinoside-5-glucoside (nasunin), respectively.

The ions produced in MS/MS were obtained through fragmentation by a specific collision energy of a selected ion precursor, applying a voltage of $4500 \mathrm{~V}$. Anthocyanins as reported in Table 2 were identified.

\subsection{Pulp polyphenols analysis}

Pulp polyphenolic compounds were analysed using the procedure reported by Ferracane et al. (2010). Samples of lyophilized pulp (1.5 g) 
A

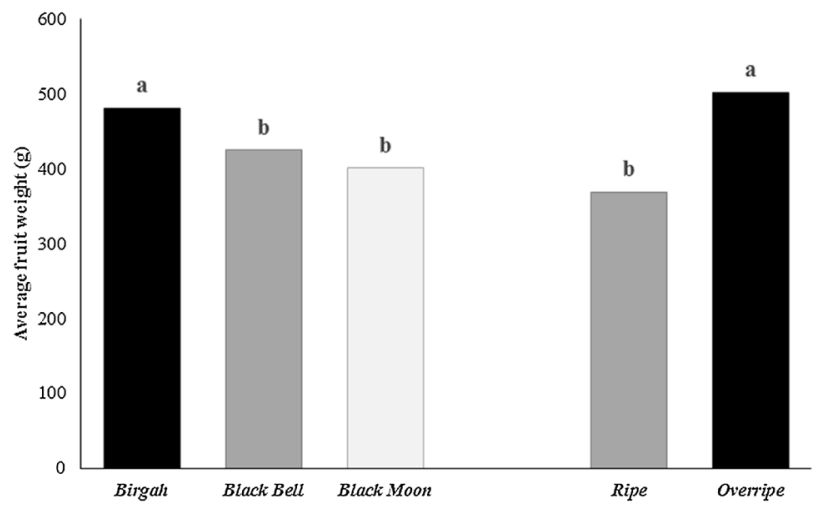

C

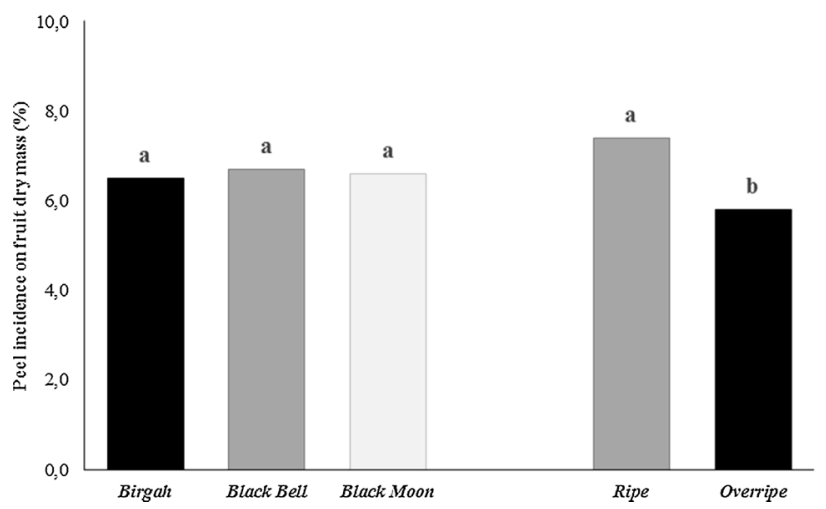

B

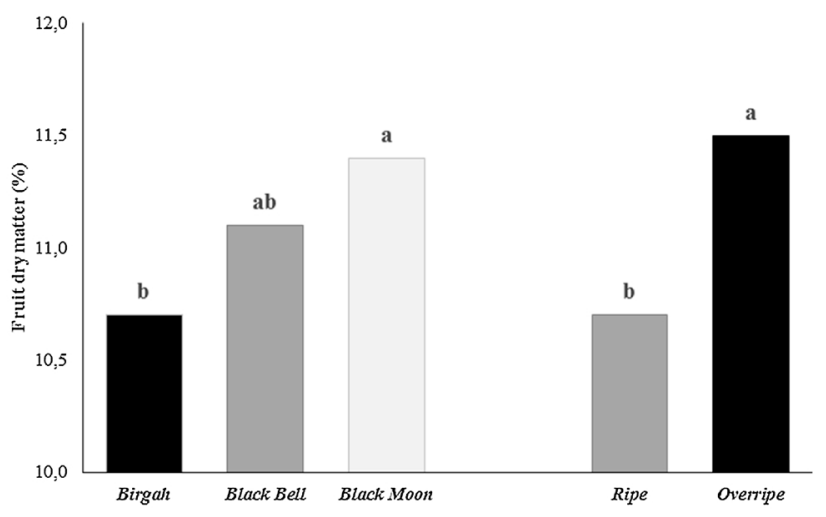

$\mathrm{D}$

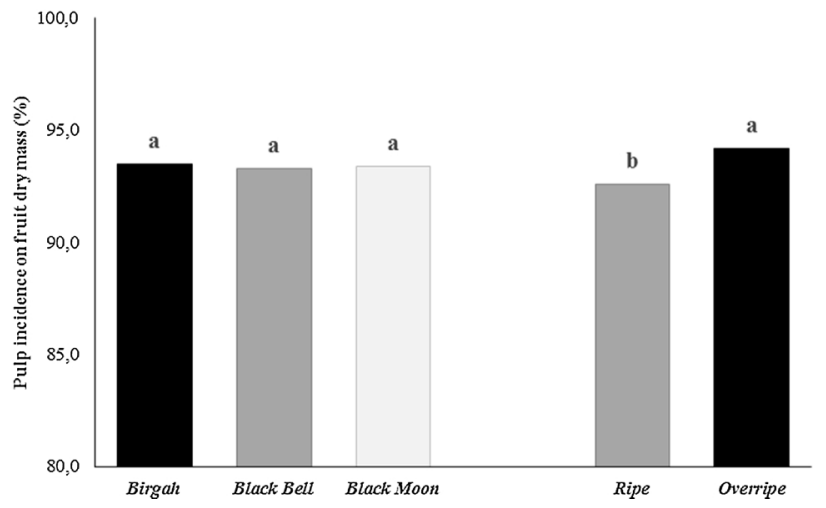

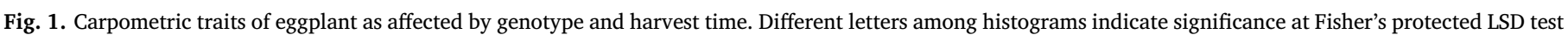
$(P \leq 0.05)$.

were extracted with $15 \mathrm{~mL}$ of methanol-water (70:30 $v / v)$ solution; hydro-alcoholic extracts were centrifuged, filtered and analysed through HPLC. In particular chromatographic separation was achieved using an HPLC apparatus equipped with two Micropumps Series 200 (PerkinElmer, Shellton, CT, USA), a UV/VIS series 200 (PerkinElmer, Shellton, CT, USA) and a Prodigy ODS $100 \AA$ column (250 mm x 4.6 $\mathrm{mm}$, particle size $5 \mu \mathrm{m}$ ) (Phenomenex, CA, USA). PDA was monitored at two wavelengths $325 \mathrm{~nm}$ and $366 \mathrm{~nm}$ for phenolic acids and for flavonols respectively. Phenols were quantified using chlorogenic acid for the calibration curve, and results were expressed as $\mathrm{mg}$ of chlorogenic acid per $\mathrm{kg}$ of dry weight of the pulp.

Caffeoyl-quinic acids (CQAs) showed a peak absorbance at 320-330 $\mathrm{nm}$ with a shoulder peak of weaker absorbance at $\sim 290 \mathrm{~nm}$ and a second one near $240 \mathrm{~nm}$.

\subsection{Pulp glycoalkaloids analysis}

Glycoalkaloids, solasonine and solamargine were extracted from 0.5 $\mathrm{g}$ samples of pulp and peel prepared as previously explained by $40 \mathrm{~mL}$ of $2 \%$ acetic acid water solution. Then samples were homogenised, centrifuged and purified with C18 column (Bond Elut C18, $500 \mathrm{mg}, 3$ $\mathrm{mL}$ ) opportunely equilibrated. Glycoalkaloids were eluted with $3 \mathrm{~mL}$ of solution methanol:water $50 \mathrm{mM} \mathrm{HCl}$ (80:20). LC/MS/MS was performed according to Paul et al. (2008) that developed an analytical method for separation of steroidal glycoalkaloids (SGAs). We used the Luna C18 column ( $250 \mathrm{~mm} \times 4.6 \mathrm{~mm}, 5 \mu)$ and mobile phase consisting of $0.5 \%(\mathrm{v} / \mathrm{v})$ formic acid in $\mathrm{H}_{2} \mathrm{O}$ (A) and ACN:2-propanol:formic acid (94.5:5:0.5, v/v/v) (B). The gradient was: 0 min, $20 \%$ B; $14 \mathrm{~min}, 30 \% \mathrm{~B} ; 20 \mathrm{~min}, 30 \% \mathrm{~B} ; 27 \mathrm{~min}, 60 \% \mathrm{~B}$ and the column was re-equilibrated to initial condition $(20 \% \mathrm{~B})$ for $10 \mathrm{~min}$ prior to next injection. The flow-rate was $1 \mathrm{~mL} / \mathrm{min}$. Results were expressed as $\mathrm{mg}$ of solanine on kg of dry weight of the pulp, calculated on the basis of a calibration curve. Identification of chromatographic peaks was based on the comparison of its retention time (RT), absorbance spectrum, and MS/MS fragments with a solanine standard. The LC-MS profile of purified extract showed three main peaks identified as solasonine ([M $+\mathrm{H}]^{+}$with $m / z$ 884), solamargine $\left([\mathrm{M}+\mathrm{H}]^{+}\right.$with $m / z$ 868) and $\beta-2$ solamargine $\left([\mathrm{M}+\mathrm{H}]^{+}\right.$with $\left.m / z 722\right)$.

\subsection{Chemicals}

All reagents and solvents HPLC grade were purchased from Merck (Darmstadt, Germany). Phenols (chlorogenic acid), anthocyanins and glycoalkaloids (solanine) standards were from Sigma (Milano, Italy).

\subsection{Residual waste of the fruits and bioactive compounds concentration}

The results of the carpometric and HPLC determinations were used to calculate the amount of residual waste (peel and pulp) and bioactive compounds (total anthocyanins, total polyphenols and total glycoalkaloids) obtainable from 1 ton of fresh fruits not destined to food market. In the case of residual waste, data were reported as $\mathrm{kg}$ of dry weight per ton of fresh fruit, whereas the concentration of bioactive compounds were expressed in $g$ per ton of fresh fruit.

\subsection{Statistical procedures}

All collected and calculated data were firstly subjected to ShapiroWilk and Levene test, in order to check for normal distribution and homoscedasticity, respectively, then to a factorial 'cultivar $\mathrm{x}$ ripening stage' analysis of variance (ANOVA), according to the experimental layout adopted in the greenhouse. Percentage data were Bliss' 
transformed before the ANOVA (untransformed data are reported and discussed) whereas multiple mean comparisons were performed through Fisher's protected least significant difference (LSD) test (at least for $P \leq 0.05$ ). A correlation analysis was also performed, to check any significant relationship among fruit chromatic coordinates and chemical composition of both, peel and pulp. All calculations were performed using Excel version 2016 (Microsoft Corporation, Redmond, WA) and Minitab version 16.1.1 (Minitab Inc., State College, PA, USA).

\section{Results}

\subsection{Carpometric traits}

Carpometric traits were significantly affected by the main factors, namely genotype and ripening stage, without significant interaction among them (Fig. 1). On the average of ripening stages, Birgah produced heavier fruits (481 g) than both Black Bell and Black Moon (413 g, on average) (Fig. 1A), whereas this last cultivar showed a higher dry matter content of the fruit (11.4\%, on average) when compared to Birgah (10.7 \%) (Fig. 1B). By delaying the harvest, all the cultivars increased both the average weight and the dry matter content of the fruit (by $36 \%$ and $6 \%$, respectively) (Fig. 1A-B), the pulp incidence on fruit weight (from 92.6\%-94.2\%), whereas decreased the incidence of the peel (from 7.4\%-5.8\%) (Fig. 1C-D).

\subsection{Chromatic traits of the peel}

All the chromatic traits of the peel were significantly affected by 'cultivar $\mathrm{x}$ ripening stage' interaction (Table 1). As the harvest was delayed at the overripening, Black Moon showed significant variations only for Hue angle (which passed from 46.1-55.0). Differently Black Bell showed significant variation for all the chromatic coordinates, namely $L^{*}$ (from 26.3-41.0), $a^{*}$ (from 5.5-14.8), $b$ * (from -2.9 to 2.3), Hue angle (from 332.1-8.9) and Chroma (from 15.0-6.2) (Table 1). Birgah showed significant variations in relation to $a^{*}$ (from 12.7-10.8), $b *$ (from -6.5 to -3.0 ), Hue angle (from 332.8-344.5) and Chroma (from 11.2-14.3) (Table 1).

\subsection{Peel anthocyanins content}

Delphinidin-3-rutinoside concentration showed a strong decrease passing from ripening to the overripening stage, both in Black Bell (-90 $\%$ ) and Black Moon (-35 \%), whereas in Birgah no significant variation

\section{Table 1}

Measured and calculated chromatic traits of the peel of eggplant fruits as affected by cultivar and harvest time. Different letters among means indicate significance at Fisher's protected LSD test $(P \leq 0.05)$.

\begin{tabular}{|c|c|c|c|c|c|c|}
\hline \multirow[t]{2}{*}{ Variable } & & \multicolumn{3}{|l|}{ Cultivar } & \multirow[b]{2}{*}{ Mean } & \multirow[b]{2}{*}{$\begin{array}{l}\text { LSD interaction } \\
(P=0.05)\end{array}$} \\
\hline & & Birgah & Black Bell & $\begin{array}{l}\text { Black } \\
\text { Moon }\end{array}$ & & \\
\hline \multirow[t]{3}{*}{$L^{*}$} & Ripe & 36.2 & 26.3 & 25.3 & $29.3 \mathrm{~b}$ & 2.5 \\
\hline & Overripe & 38.2 & 41.0 & 26.4 & $35.2 \mathrm{a}$ & \\
\hline & Mean & $37.2 \mathrm{a}$ & $33.7 \mathrm{~b}$ & $25.8 \mathrm{c}$ & & \\
\hline \multirow[t]{3}{*}{$a^{*}$} & Ripe & 12.7 & 5.5 & 2.6 & $6.9 \mathrm{~b}$ & 1.1 \\
\hline & Overripe & 10.8 & 14.8 & 2.1 & $9.2 \mathrm{a}$ & \\
\hline & Mean & $11.8 \mathrm{a}$ & $10.1 \mathrm{~b}$ & $2.3 \mathrm{c}$ & & \\
\hline \multirow[t]{3}{*}{$b^{*}$} & Ripe & -6.5 & -2.9 & 2.7 & $-2.2 \mathrm{~b}$ & 0.6 \\
\hline & Overripe & -3.0 & 2.3 & 3.0 & $0.8 \mathrm{a}$ & \\
\hline & Mean & $-4.8 c$ & $-0.3 b$ & $2.8 \mathrm{a}$ & & \\
\hline \multirow[t]{3}{*}{ Hue angle } & Ripe & 332.8 & 332.1 & 46.1 & $237.0 \mathrm{a}$ & 4.3 \\
\hline & Overripe & 344.5 & 8.9 & 55.0 & $136.1 \mathrm{~b}$ & \\
\hline & Mean & $338.7 \mathrm{a}$ & $170.5 \mathrm{~b}$ & $50.5 \mathrm{c}$ & & \\
\hline \multirow[t]{3}{*}{ Chroma } & Ripe & 11.2 & 15.0 & 3.8 & $10.0 \mathrm{a}$ & 1.1 \\
\hline & Overripe & 14.3 & 6.2 & 3.6 & $8.0 \mathrm{~b}$ & \\
\hline & Mean & $12.7 \mathrm{a}$ & $10.6 \mathrm{~b}$ & $3.7 \mathrm{c}$ & & \\
\hline
\end{tabular}

was observed (Table 2). By delaying the harvest, all the tested cultivars showed a significant reduction of delphinidin-3-rutinoside-5-glucoside too, with reductions equal to $63 \%, 55 \%$ and $49 \%$ in Black Moon, Birgah and Black Bell, respectively (Table 2). Similarly, delphinidin-3coumaroylrutinoside-5-glucoside concentration showed a strong reduction passing from ripening to the overripening stage, with Black Bell showing the highest reduction (-95\%), followed by Birgah (-80\%) and Black Moon (-78 \%) (Table 2).

Overall all these modifications were mirrored in the concentration of total anthocyanins which, passing from ripening to the overripening stage, dramatically decreased firstly in Black Bell (-92\%) followed by Birgah and Black Moon (-75 \%) (Table 2).

In Fig. 2 is reported a typical HPLC chromatogram of peel anthocyanins extracted monitored at $520 \mathrm{~nm}$.

\subsection{Pulp polyphenols content}

The 5-O-caffeoylquinic acid proved to be the most abundant among the polyphenols detected, whose concentration in Black Moon did not displayed significant variation across ripening stages (Table 3). On the contrary, Black Bell showed a significant increase of this compound passing from ripening to the overripening stage $(+1.4 \%)$ followed by Birgah (+27 \%) (Table 3).

Differently, Black Moon was the only cultivar showing a significant decrease of 3,5-O-dicaffeoylquinic acid concentration at the overripening stage $(-16 \%)$ (Table 3$)$.

The 3-acetyl-5-caffeoylquinic acid concentration proved to increase passing from ripening to the overripening stage, with a steeper trend both in Black Bell (+478 \%) followed by both Birgah (+248 \%) and Black Moon (+205\%) (Table 3).

A similar upward trend was noticed for the other unidentified caffeoylquinic derivatives too, whose concentration, passing from ripening to the overripening stages, increased by $68 \%, 35 \%$ and $25 \%$ in Black Moon, Birgah and Black Bell, respectively (Table 3).

$\mathrm{N}$-caffeoyl-putrescine derivatives were identified in our samples (Table 3). Their concentration did not varied across ripening stages in Black Bell, whereas increased by $62 \%$ and $57 \%$ in Birgah and Black Moon, respectively (Table 3).

Overall, the total caffeoylquinic acids concentration was significantly affected by 'cultivar $\mathrm{x}$ ripening stage'. Indeed, passing from ripening to the overripening stage, it significantly increased by $100 \%$, $31 \%$ and $10 \%$ in Black Bell, Birgah and Black Moon, respectively (Table 3).

A typical HPLC profile of phenolic phytochemical extracted from eggplant pulp sample is reported in Fig. 3.

\subsection{Pulp glycoalkaloids content}

At the overripening stage the content of $\alpha$-solasonine increased in all the tested cultivars, with percentage increase ranging from $186 \%$ (Black Moon) to $2.6 \%$ (Birgah) (Table 4). Similarly, $\alpha+\beta$ solamargine concentration was significantly higher at the overripening stage, as it increased by 216, 189 and $182 \%$ in Black Bell, Black Moon and Birgah, respectively (Table 4).

As a results of these modifications, at the overripening stage the pulp glycoalkaloids content significantly increased in all the cultivars under study, namely Birgah ( $+212 \%)$, Black Bell $(+212 \%)$ and Black Moon (+189\%) (Table 4). In Fig. 4 are reported TIC and XICs chromatograms of pulp extract investigated by LC/MS/MS.

\subsection{Residual waste of the fruit and bioactive compounds}

The mean residual biomass of the fruit was $111 \mathrm{~kg} \mathrm{DW} \mathrm{t}^{-1}$ fresh fruit, with no differences among genotypes in terms of peel nor in terms of pulp residual waste (Table 5). Both variables showed an opposite trend across ripening stages, as the residual waste of the peel decreased at the 
Table 2

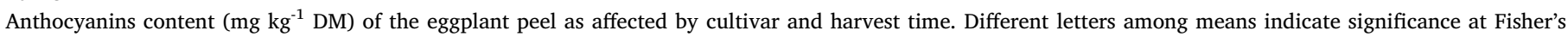
protected LSD test $(P \leq 0.05)$.

\begin{tabular}{|c|c|c|c|c|c|c|}
\hline \multirow[t]{2}{*}{ Variable } & & \multicolumn{3}{|c|}{ Cultivar } & \multirow[b]{2}{*}{ Mean } & \multirow[b]{2}{*}{ LSD interaction $(P=0.05)$} \\
\hline & & Birgah & Black Bell & Black Moon & & \\
\hline \multirow[t]{3}{*}{ Delphinidin- 3-rutinoside } & Ripe & 303 & 878 & 133 & $438 \mathrm{a}$ & 38 \\
\hline & Overripe & 299 & 91 & 86 & $159 \mathrm{~b}$ & \\
\hline & Mean & $301 \mathrm{~b}$ & $484 \mathrm{a}$ & $109 \mathrm{c}$ & & \\
\hline \multirow[t]{3}{*}{ Delphinidin-3-rutinoside-5- glucoside } & Ripe & 182 & 298 & 102 & $194 \mathrm{a}$ & 20 \\
\hline & Overripe & 82 & 153 & 37 & $91 \mathrm{~b}$ & \\
\hline & Mean & $132 \mathrm{~b}$ & 226 a & $70 \mathrm{c}$ & & \\
\hline \multirow[t]{3}{*}{ Delphinidin-3-coumaroylrutinoside-5-glucoside } & Ripe & 5320 & 5766 & 2228 & 4438 a & 387 \\
\hline & Overripe & 1080 & 290 & 485 & $618 \mathrm{~b}$ & \\
\hline & Mean & $3200 \mathrm{a}$ & $3028 \mathrm{a}$ & $1357 \mathrm{~b}$ & & \\
\hline \multirow[t]{3}{*}{ Total anthocyanins } & Ripe & 5804 & 6941 & 2463 & $5070 \mathrm{a}$ & 262 \\
\hline & Overripe & 1461 & 534 & 608 & $868 \mathrm{~b}$ & \\
\hline & Mean & $3633 a$ & $3738 \mathrm{a}$ & $1535 \mathrm{~b}$ & & \\
\hline
\end{tabular}

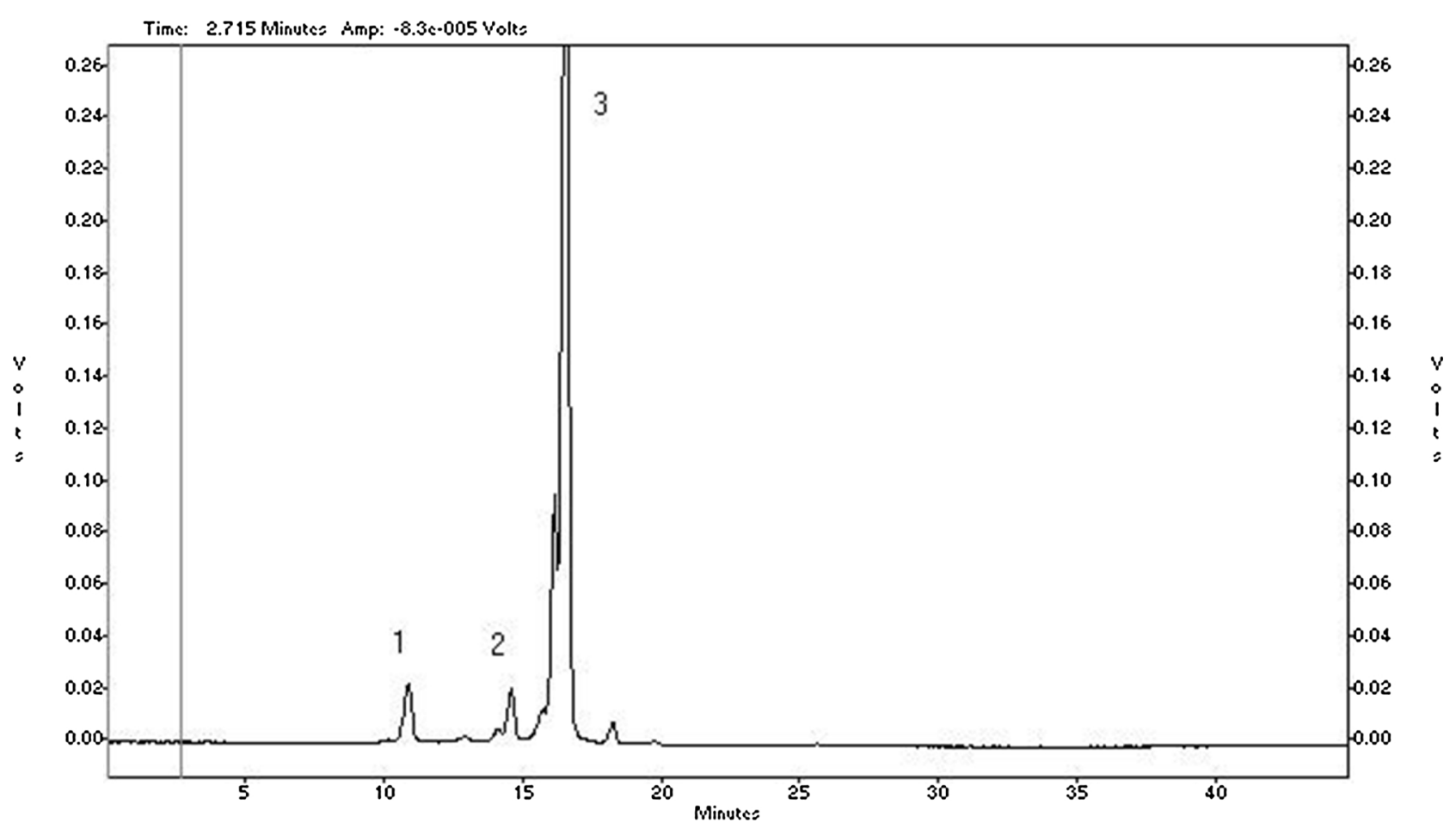

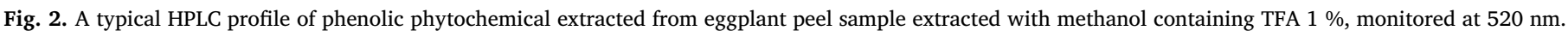

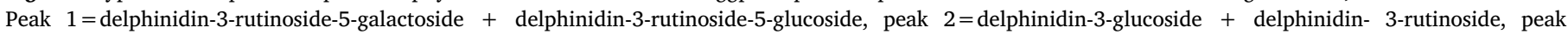
$3=$ nasunin.

overripening (by $1.4 \mathrm{~kg} \mathrm{DW} \mathrm{t}^{-1}$ fresh fruit), whereas that of the pulp significantly increased (by $7.3 \mathrm{~kg} \mathrm{DW} \mathrm{t}^{-1}$ fresh fruit) (Table 5).

In all the cultivars under study total anthocyanins concentration was higher at commercial ripening stage, whereas at overripening they showed a decrease equal to $95 \%, 80 \%$ and $79 \%$ in Black Bell, Black Moon and Birgah, respectively (Table 5). An opposite trend was noticed for total caffeoylquinic acids concentration of residual waste, whose concentration increased by $111 \%, 41 \%$ and $20 \%$ in Black Bell, Birgah and Black Moon, respectively, passing from ripening to the overripening stage (Table 5). Similarly, total glycoalkaloids concentration of residual waste increased by delaying the harvest in a genotype-dependent way, rising by $245 \%, 227 \%$ and $215 \%$ in Birgah, Black Bell, and Black Moon, respectively (Table 5).

\subsection{Correlation among chromatic traits of the peel and biochemical variables}

Overall 70 correlations were analysed, of which 37 (53\% of total) showed significance, revealing 22 negative and 15 positive relationships (Table 6). In the case of polyphenols, 21 out of 30 correlations (70 $\%$ of total) were significant, whereas they were 6 out of 15 (40\%) for glycoalkaloids and 8 out $20(40 \%)$ for anthocyanins. Overall, $L^{*}, a^{*}$ and Chroma gave 3 significant correlations each, whereas for both $b^{*}$ and Hue angle they were 14. As a result, all the biochemical variables were significantly correlated with at least 2 chromatic coordinates. Among the negative correlations, the highest significance was found among 3,5-O-dicaffeoylquinic acid concentration of the pulp, $a^{*}$ 
Table 3

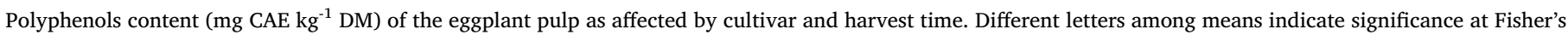
protected LSD test $(P \leq 0.05)$.

\begin{tabular}{|c|c|c|c|c|c|c|}
\hline \multirow[t]{2}{*}{ Variable } & & \multicolumn{3}{|l|}{ Cultivar } & \multirow[b]{2}{*}{ Mean } & \multirow[b]{2}{*}{ LSD interaction $(P=0.05)$} \\
\hline & & Birgah & Black Bell & Black Moon & & \\
\hline \multirow[t]{3}{*}{ 5-O-caffeoylquinic acid } & Ripe & 5099 & 3006 & 7253 & 5119 b & 1421 \\
\hline & Overripe & 6467 & 6127 & 7395 & $6663 \mathrm{a}$ & \\
\hline & Mean & $5783 \mathrm{~b}$ & $4567 \mathrm{c}$ & $7324 \mathrm{a}$ & & \\
\hline \multirow[t]{3}{*}{ 3,5-O-dicaffeoylquinic acid } & Ripe & 20 & 108 & 388 & $172 \mathrm{a}$ & 36 \\
\hline & Overripe & 14 & 106 & 325 & $148 \mathrm{~b}$ & \\
\hline & Mean & $17 \mathrm{c}$ & $107 \mathrm{~b}$ & $357 \mathrm{a}$ & & \\
\hline \multirow[t]{3}{*}{ 3-acetyl-5-caffeoylquinic acid } & Ripe & 38 & 48 & 110 & $65 \mathrm{~b}$ & 25 \\
\hline & Overripe & 146 & 275 & 336 & $242 \mathrm{a}$ & \\
\hline & Mean & $92 \mathrm{c}$ & $162 \mathrm{~b}$ & $223 \mathrm{a}$ & & \\
\hline \multirow[t]{3}{*}{ Other caffeoylquinic acid derivatives } & Ripe & 68 & 84 & 114 & $89 \mathrm{~b}$ & 27 \\
\hline & Overripe & 92 & 105 & 192 & $130 \mathrm{a}$ & \\
\hline & Mean & $80 \mathrm{~b}$ & $95 \mathrm{~b}$ & 153 a & & \\
\hline \multirow[t]{3}{*}{$\mathrm{N}$-caffeoyl putrescine derivatives } & Ripe & 381 & 250 & 787 & $473 \mathrm{a}$ & 146 \\
\hline & Overripe & 619 & 378 & 1236 & $744 \mathrm{a}$ & \\
\hline & Mean & $500 \mathrm{~b}$ & $314 \mathrm{c}$ & $1012 \mathrm{a}$ & & \\
\hline \multirow[t]{3}{*}{ Total caffeoylquinic acids } & Ripe & 5606 & 3496 & 8652 & $5918 \mathrm{~b}$ & NS \\
\hline & Overripe & 7338 & 6991 & 9485 & 7938 a & \\
\hline & Mean & $6472 \mathrm{~b}$ & $5244 \mathrm{c}$ & 9068 a & & \\
\hline
\end{tabular}

$(-0.812 * * *)$ and Chroma $(-0.809 * * *)$, as well as among Hue angle, $\alpha+$ $\beta$ solamargine concentration of the pulp $\left(-0.787^{* * *}\right)$ and total glycoalkaloids content of residual waste $\left(-0.753^{* * *}\right)$. Differently, the strongest relationship in the data frame of positive correlations was found among $b^{*}$ and $\alpha+\beta$ solamargine concentration of the pulp $(0.790 * * *), 3,5$-O-dicaffeoylquinic acid content of the pulp $(0.780 * * *)$, total glycoalkaloids content of residual waste $\left(0.773^{* * *}\right)$ and $\alpha$-solasonine content of the pulp $\left(0.728^{* * * *}\right)$ (Table 6).

\section{Discussion}

Under the specific conditions of our experiment, the ripening process induced considerable modifications of the eggplant fruits, both from a carpometric and biochemical viewpoint. The main examples of morphological variations found with proceeding ripening were an increase of the fresh and dry weight of the fruits, as well as an increase of the weight incidence of the pulp at the expense of the peel, consistent
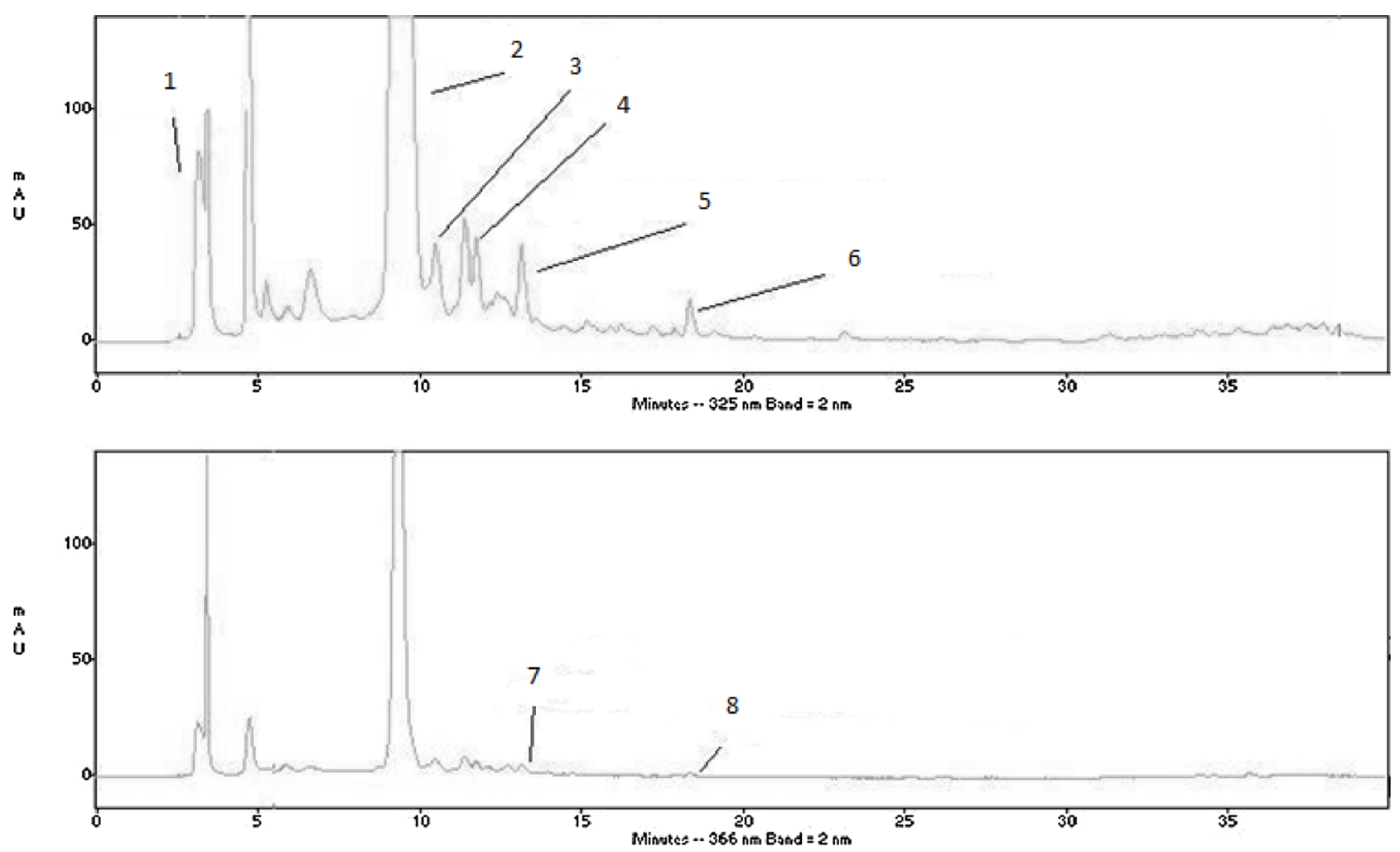

Fig. 3. High performance liquid chromatography phenolic components of eggplant pulp sample extracted with $70 \%$ aqueous methanol, monitored at 325 and 366 nm. N-caffeoyl putrescine derivatives (peak 1), 5-Caffeoylquinic acid (peak 2), caffeic acid coniugate (peak 3), caffeoyl quinic acid derivatives (peak 4), 3-acetyl-5caffeoyl quinic acid (peak 5), 3-5-dicaffeoyl quinic acid (peak 6), myricetin galattoside (peak 7), quercetin rhamnopyranoside (peak 8). 
Table 4

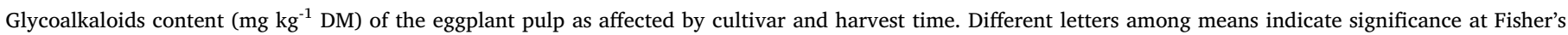
protected LSD test $(P \leq 0.05)$.

\begin{tabular}{|c|c|c|c|c|c|c|}
\hline \multirow[t]{2}{*}{ Variable } & & \multicolumn{3}{|c|}{ Cultivar } & \multirow[b]{2}{*}{ Mean } & \multirow[b]{2}{*}{ LSD interaction $(P=0.05)$} \\
\hline & & Birgah & Black Bell & Black Moon & & \\
\hline \multirow[t]{3}{*}{$\alpha$-solasonine } & Ripe & 75 & 132 & 222 & $143 \mathrm{~b}$ & 57 \\
\hline & Overripe & 282 & 393 & 634 & $436 \mathrm{a}$ & \\
\hline & Mean & $178 \mathrm{c}$ & $263 \mathrm{~b}$ & $428 \mathrm{a}$ & & \\
\hline \multirow[t]{3}{*}{$\alpha+\beta$ solamargine } & Ripe & 158 & 479 & 568 & $402 \mathrm{~b}$ & 174 \\
\hline & Overripe & 446 & 1513 & 1640 & $1200 \mathrm{a}$ & \\
\hline & Mean & $302 \mathrm{~b}$ & $996 \mathrm{~b}$ & $1104 \mathrm{a}$ & & \\
\hline \multirow[t]{3}{*}{ Total glycoalkaloids } & Ripe & 233 & 611 & 787 & $544 \mathrm{~b}$ & 211 \\
\hline & Overripe & 728 & 1906 & 2274 & $1636 \mathrm{a}$ & \\
\hline & Mean & $481 \mathrm{c}$ & $1259 \mathrm{~b}$ & $1530 \mathrm{a}$ & & \\
\hline
\end{tabular}

with the volumetric expansion accompanying the weight gain of the berries. These changes in carpometric traits were closely related to a shift in chromatic traits of the epicarp, whose intensity, in turn, was strongly dependent upon the external appearance reached by the fruits at their commercial ripening stage. As a general trend, with the advance of ripening stage the epicarp of the cultivars showed an increase in $L^{*}$ and $b^{*}$, together with wider differences between their Hue angles, indicating a shift toward lighter and more distinct colours. On the other hand, the different shift of $a^{*}$ and Chroma recorded among cultivars revealed some differences in colour variation across ripening stages, so suggesting different kinetics in the degradative reactions of the epicarp pigments.

The epicarp appearance of the eggplant fruit is the result of chromatic interactions among several pigments, among which anthocyanins represent by far the majority fraction in the marketable product (D'Anna and Sabatino, 2013; Niño-Medina et al., 2017). Three main anthocyanins were detected in the studied germplasm, namely delphinidin-3-rutinoside, delphinidin-3-rutinoside-5-glucoside and delphinidin-3-coumaroylrutinoside-5-glucoside (nasunin). As reported in a previous study (Noda et al., 2000), this last compound resulted largely prevailing within the anthocyanin fraction of all the cultivars under study (from 82 to $93 \%$ of total). On the basis of the germplasm subdivision proposed by (Azuma et al., 2008), this leads us to consider all the cultivar we tested falling into the Japanese eggplant type (i.e. nasunin containing genotype), which are opposed to non-Japanese type (delphinidin-3-rutinoside containing genotypes). Interestingly, the

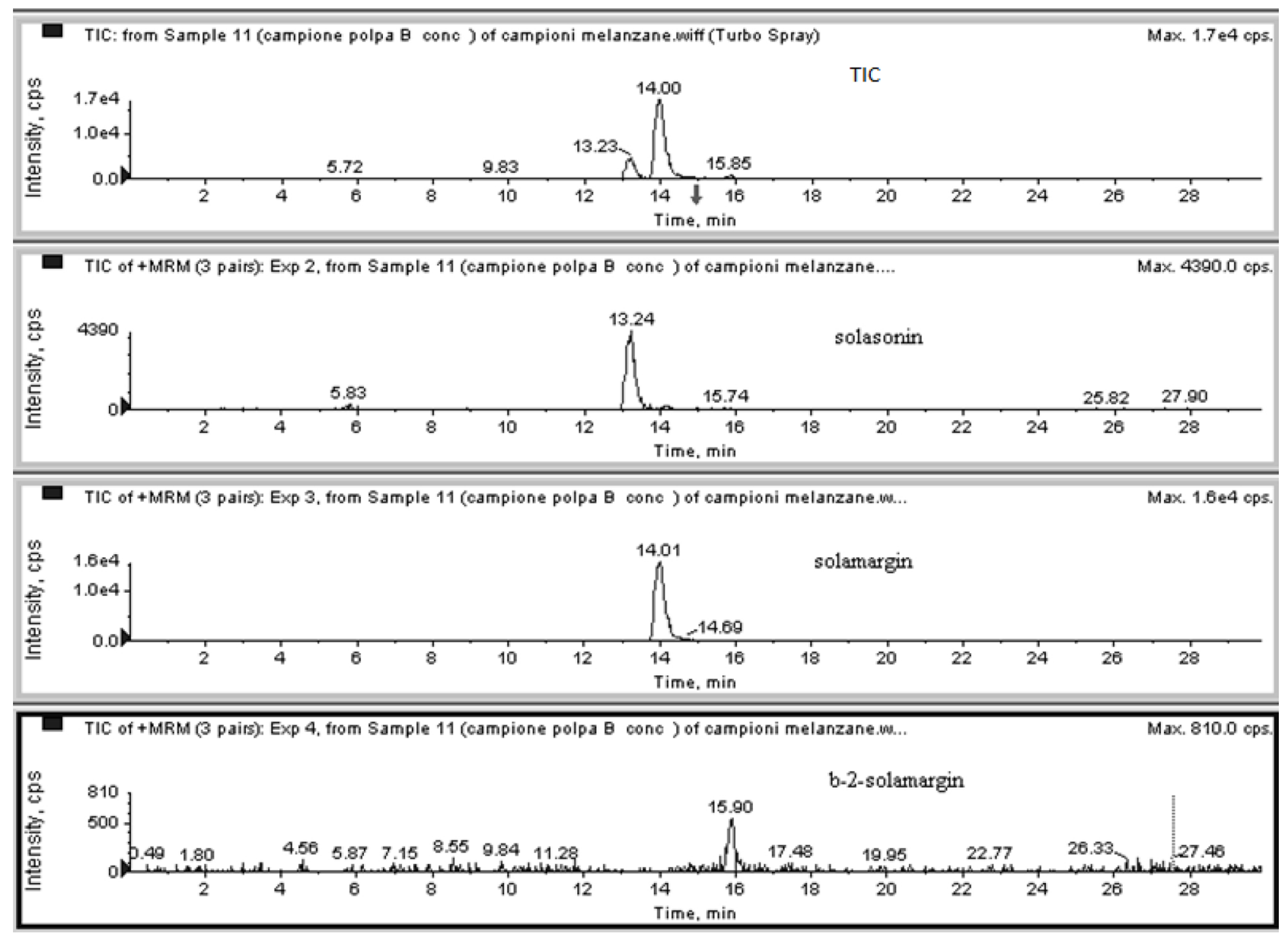

Fig. 4. TIC and Extracted ion chromatograms (XICs) of glycoalkaloids (solasonine tr $=13.24$ min, $\alpha$-solamargine $\operatorname{tr}=14.01$ min and $\beta$-2-solamargine $\operatorname{tr}=15.90$ min) from eggplant pulp obtained using an API 3000 triple quadrupole mass spectrometer. 
Table 5

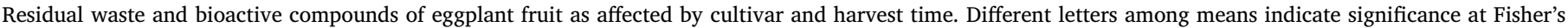
protected LSD test $(P \leq 0.05)$. NS: not significant.

\begin{tabular}{|c|c|c|c|c|c|c|}
\hline \multirow[t]{2}{*}{ Variable } & & \multicolumn{3}{|l|}{ Cultivar } & \multirow[b]{2}{*}{ Mean } & \multirow[b]{2}{*}{ LSD interaction $(P=0.05)$} \\
\hline & & Birgah & Black Bell & Black Moon & & \\
\hline \multirow[t]{3}{*}{ Peel residual waste (kg DW $\mathrm{t}^{-1}$ fresh fruit) } & Ripe & 7.4 & 8.4 & 8.1 & $8.0 \mathrm{a}$ & NS \\
\hline & Overripe & 6.5 & 6.4 & 6.8 & $6.6 \mathrm{~b}$ & \\
\hline & Mean & $7.0 \mathrm{a}$ & $7.4 \mathrm{a}$ & $7.5 \mathrm{a}$ & & \\
\hline \multirow[t]{3}{*}{ Pulp residual waste (kg DW $\mathrm{t}^{-1}$ fresh fruit) } & Ripe & 96.7 & 101.3 & 101.7 & $99.9 \mathrm{~b}$ & NS \\
\hline & Overripe & 103.8 & 106.8 & 111.1 & $107.2 \mathrm{a}$ & \\
\hline & Mean & $100.2 \mathrm{~b}$ & $104.0 \mathrm{ab}$ & $106.4 \mathrm{a}$ & & \\
\hline \multirow[t]{3}{*}{ Total anthocyanins ( $\mathrm{g} \mathrm{t}^{-1}$ fresh fruit) } & Ripe & 43.1 & 58.6 & 20.1 & $40.6 \mathrm{a}$ & 5.0 \\
\hline & Overripe & 9.5 & 3.4 & 4.1 & $5.7 \mathrm{~b}$ & \\
\hline & Mean & $26.3 \mathrm{~b}$ & $31.0 \mathrm{a}$ & $12.1 \mathrm{c}$ & & \\
\hline \multirow[t]{3}{*}{ 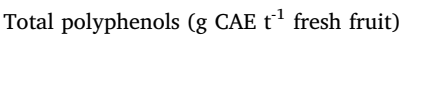 } & Ripe & 542 & 354 & 882 & $593 \mathrm{~b}$ & 186 \\
\hline & Overripe & 762 & 746 & 1054 & $854 \mathrm{a}$ & \\
\hline & Mean & $652 \mathrm{~b}$ & $550 \mathrm{c}$ & 955 a & & \\
\hline \multirow[t]{3}{*}{ Total glycoalkaloids ( $\mathrm{g} \mathrm{t}^{-1}$ fresh fruit) } & Ripe & 22 & 62 & 80 & $55 \mathrm{~b}$ & 21 \\
\hline & Overripe & 76 & 203 & 252 & $177 \mathrm{a}$ & \\
\hline & Mean & $49 \mathrm{c}$ & $133 \mathrm{~b}$ & $166 \mathrm{a}$ & & \\
\hline
\end{tabular}

relative concentration among delphinidin-3-rutinoside and nasunin showed great variation among genotypes, being higher in Black Bell than in the other genotypes. This suggest the possibility to obtain in breeding programs some transition forms between Japanese and nonJapanese types, an hypothesis consistent with the multifactorial nature of the peel anthocyanins content (Toppino et al., 2016). Overall, the total anthocyanins concentration we found at commercial ripening stage, especially for Birgah and Black Bell is higher than other highly pigmented genotypes of carrot, cauliflower, potato or onion ( $\mathrm{Li}$ et al., 2012), so justifying the growing interest given to this crop for both food and industrial application purposes. The shift in the epicarp colour at the overripening stage, was accompanied by a dramatic decrease of the total anthocyanins content of the peel, a future which is consistent with their nature of developmentally regulated pigments (Steyn et al., 2002). This phenomenon regarded mainly nasunin and, among the cultivars, was more evident in Black Bell, less in Birgah. This last genotype showed also a less variable delphinidin-3-rutinoside concentration across ripening stages, so suggesting different activation patterns of peel catabolic reactions leading up to physiological ripening.

Following the criteria used for classification of phenolic compounds in eggplant (Stommel and Whitaker, 2003; Whitaker and Stommel, 2003), in our samples we identified polyphenols belonging to group 1 (chlorogenic acids isomers), group 2 (isochlorogenic acid isomers), group 3 (hydroxycinnamic acid amide conjugates) and group 5 (acetylated chlorogenic acid isomers). According to previous observations (Mennella et al., 2010, 2012; Prohens et al., 2013), chlorogenic acid was the preeminent monomeric phenol compound detected, accounting for $82-89 \%$ of total polyphenols concentration of the eggplant pulp. It has been reported that this hydroxycinnamic acid derivative displays an uneven distribution within the eggplant berry, reaching a higher concentration in the inner pulp than in the outer one (Zaro et al., 2014, 2015). At commercial ripening stage we found a remarkable concentration of total polyphenols in the eggplant pulp (up to $8652 \mathrm{mg}$ $\mathrm{kg}^{-1} \mathrm{DW}$ on average), so confirming the leading role as functional food of this fruit among the Solanaceae members (Gürbüz et al., 2018). Despite this, as previously reported (Mennella et al., 2012), we found ample differences among cultivars for this variable, which was mostly due to the genotype-dependent differences in 5-O-caffeoylquinic acid. However, the delay of harvest at the overripening stage allowed to reach two main targets, specifically an increase in total polyphenols content in all the cultivars (by $34 \%$, on average) and a reduction of the difference among them in terms of total caffeoylquinic acids content. Indeed, for this variable the coefficient of variation among cultivars was reduced from 44 to $17 \%$, passing from ripening to overripening stage (data not shown), overall indicating the possible development of an appropriate agronomic protocols in the perspective of constructing a reliable eggplant-based supply chain for industrial processors.

As expected, the glycoalkaloids fraction of the eggplant pulp was

Table 6

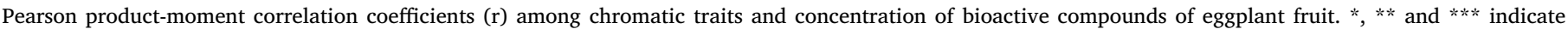
significance at $P<0.05,0.01$ and 0.001 , respectively. NS: not significant.

\begin{tabular}{|c|c|c|c|c|c|}
\hline & $L^{*}$ & $a^{*}$ & $b^{*}$ & Hue angle & Chroma \\
\hline 5-O-caffeoylquinic acid (mg CAE $\left.\mathrm{kg}^{-1} \mathrm{DW}\right)$ & NS & NS & 0.578 * & $-0.591 * *$ & NS \\
\hline 3.5-O-dicaffeoylquinic acid (mg CAE kg ${ }^{-1} \mathrm{DW}$ ) & $-0.728 * * *$ & $-0.812 * * *$ & $0.780 * * *$ & $-0.724 * * *$ & $-0.809 * * *$ \\
\hline 3-acetyl-5-caffeoylquinic acid (mg CAE kg ${ }^{-1} \mathrm{DW}$ ) & 0.508 * & NS & $0.621 * *$ & $-0.657 * *$ & NS \\
\hline Caffeoylquinic acid derivatives (mg CAE kg ${ }^{-1} \mathrm{DW}$ ) & NS & $-0.557 *$ & $0.691 * *$ & $-0.638 * *$ & $-0.574 *$ \\
\hline $\mathrm{N}$-caffeoyl putrescine derivatives (mg CAE $\mathrm{kg}^{-1} \mathrm{DW}$ ) & $-0.483 *$ & $-0.661 * *$ & $0.607 * *$ & $-0.537 *$ & $-0.651 * *$ \\
\hline$\alpha$-solasonine $\left(\mathrm{mg} \mathrm{kg}^{-1} \mathrm{DW}\right)$ & NS & NS & $0.728 * * *$ & $-0.653 * *$ & NS \\
\hline$\alpha+\beta$ solamargine $\left(\mathrm{mg} \mathrm{kg}^{-1} \mathrm{DW}\right)$ & NS & NS & $0.790 * * *$ & $-0.787 * * *$ & NS \\
\hline Delphinidin- 3-rutinoside ( $\left.\mathrm{mg} \mathrm{kg}^{-1} \mathrm{DW}\right)$ & NS & NS & $-0.548 *$ & $0.697 * *$ & NS \\
\hline Delphinidin-3-rutinoside-5- glucoside ( $\left.\mathrm{mg} \mathrm{kg}^{-1} \mathrm{DW}\right)$ & NS & NS & $-0.497 *$ & $0.479 *$ & NS \\
\hline Delphinidin-3-coumaroylrutinoside-5-glucoside $\left(\mathrm{mg} \mathrm{kg}^{-1} \mathrm{DW}\right)$ & NS & NS & $-0.727 * * *$ & $0.675 * *$ & NS \\
\hline Residual waste (kg DW t ${ }^{-1}$ fresh fruit) & NS & NS & $0.679 * *$ & $-0.520 *$ & NS \\
\hline Total anthocyanins ( $\mathrm{g} \mathrm{t}^{-1}$ fresh fruit) & NS & NS & $0.712 * * *$ & $-0.698 * *$ & NS \\
\hline Total polyphenols ( $\mathrm{g}$ CAE $t^{-1}$ fresh fruit) & NS & NS & $0.773 * * *$ & $-0.753 * * *$ & NS \\
\hline Total glycoalkaloids ( $\mathrm{g} \mathrm{t}^{-1}$ fresh fruit) & NS & NS & $-0.664 * *$ & $0.655 * *$ & NS \\
\hline
\end{tabular}


represented by $\alpha$-solasonine and $\alpha+\beta$-solamargine, the latter compounds representing on average $73 \%$ of total content in the tested cultivars. These are nitrogen-containing steroidal glycosides commonly found in Solanum genus, sharing the same aglycone solasodine, whereas differing for the nature of the involved trioses (solatriose and chacotriose, respectively) (Al Sinani and Eltayeb, 2017). According to previous experiments (Mennella et al., 2012), these glycoalkaloids showed ample variations among the cultivars we tested (especially solamargine), with increasing concentrations as the harvest was delayed, both reaching the highest concentration in Black Moon at the overripening stage.

All the above-mentioned modifications gave interesting results from the perspective of eggplant utilization for industrial purposes. Indeed, in our experiment every ton of eggplant fruits not destined to fresh consumption gave up to 6.4-8.4 and 96.7-111.1 kg DW in terms of peel and pulp residual, respectively. From these residuals a quantity up to 59 $\mathrm{g}$ of total anthocyanins, $1054 \mathrm{~g}$ CAE of total caffeoylquinic acids and $252 \mathrm{~g}$ of total glycoalkaloids could be destined to the industrial processors, depending upon cultivar and fruit ripening stage. To this end, the harvest at commercial ripening maximized the gain in terms of the anthocyanins fraction, given its higher concentration (most of all in terms of nasunin), as well as the higher incidence of the peel on fruit dry weight. On the contrary, the overripening stage maximized both total caffeoylquinic acids and glycoalkaloids in the residual waste, as a combination of an increase in the dry matter content of the fruit, the weight incidence of the pulp and the concentration of both classes of compounds. Among the genotype under study, which were chosen because of their large diffusion in the reference area, Black Moon and Black Bell showed interesting characteristics in terms of total caffeoylquinic and glycoalkaloids content, with Black Bell showing also a high yield of total peel anthocyanin content, followed by Birgah. These varietal differences could be exploited for a better valorization of the raw material, on the basis of different specific requests by the industrial processors.

The phytochemicals yield recorded in this study suggests that the residual waste of eggplant fruits can be considered as an exploitable source of highly valuable phytochemicals, at least in relation to caffeoylquinic acids and glycoalkaloids. For these two classes of compounds a direct link between farmers and industrial processors seems conceivable, provided that agronomical factors such the choice of genotype and harvest time are properly managed. To this end, one of the most interesting results of this study is the pool of highly significant correlations we found among $b^{*}$ axis, Hue angle and the trends of the different chemical compounds detected in all the tested genotypes. This suggest that these parameters, after cultivar-specific calibrations, could represent rapid and non-destructive means to better identify the best harvest time to maximize the phytochemical gain from the eggplant fruits.

\section{Appendix A. Supplementary data}

Supplementary material related to this article can be found, in the online version, at doi:https://doi.org/10.1016/j.scienta.2019.109023.

\section{References}

Al Sinani, S.S.S., Eltayeb, E.A., 2017. The steroidal glycoalkaloids solamargine and solasonine in Solanum plants. South African J. Bot. 112, 253-269. https://doi.org/10. 1016/j.sajb.2017.06.002.

Alkoaik, F., Ghaly, A.E., 2006. Influence of dairy manure addition on the biological and thermal kinetics of composting of greenhouse tomato plant residues. Waste Manag. 26, 902-913. https://doi.org/10.1016/J.WASMAN.2005.11.023.

Azuma, K., Ohyama, A., Ippoushi, K., Ichiyanagi, T., Takeuchi, A., Saito, T., Fukuoka, H., 2008. Structures and antioxidant activity of anthocyanins in many accessions of eggplant and its related species. J. Agric. Food Chem. 56, 10154-10159. https://doi. org $/ 10.1021 /$ jf801322m.

Bong, C.P.C., Lim, L.Y., Ho, W.S., Lim, J.S., Klemeš, J.J., Towprayoon, S., Ho, C.S., Lee, C.T., 2017. A review on the global warming potential of cleaner composting and mitigation strategies. J. Clean. Prod. 146, 149-157. https://doi.org/10.1016/j. jclepro.2016.07.066.

D’Anna, F., Sabatino, L., 2013. Morphological and agronomical characterization of eggplant genetic resources from the Sicily area. J. Food, Agric. Environ. 11, 401-404.

Faostat, 2018: http://www.fao.org/faostat/en/ (accessed on 2018/09/29).

Ferarsa, S., Zhang, W., Moulai-Mostefa, N., Ding, L., Jaffrin, M.Y., Grimi, N., 2018. Recovery of anthocyanins and other phenolic compounds from purple eggplant peels and pulps using ultrasonic-assisted extraction. Food Bioprod. Process. 109, 19-28. https://doi.org/10.1016/j.fbp.2018.02.006.

Ferracane, R., Graziani, G., Gallo, M., Fogliano, V., Ritieni, A., 2010. Metabolic profile of the bioactive compounds of burdock (Arctium lappa) seeds, roots and leaves. J. Pharm. Biomed. Anal. 51, 399-404. https://doi.org/10.1016/J.JPBA.2009.03.018.

Friedman, M., 2015. Chemistry and anticarcinogenic mechanisms of glycoalkaloids produced by eggplants, potatoes, and tomatoes. J. Agric. Food Chem. 63, 3323-3337. https://doi.org/10.1021/acs.jafc.5b00818.

Gürbüz, N., Uluişik, S., Frary, A., Frary, A., Doğanlar, S., 2018. Health benefits and bioactive compounds of eggplant. Food Chem. 268, 602-610. https://doi.org/10. 1016/j.foodchem.2018.06.093.

Ingrao, C., Faccilongo, N., Di Gioia, L., Messineo, A., 2018. Food waste recovery into energy in A circular economy perspective: a comprehensive review of aspects related to plant operation and environmental assessment. J. Clean. Prod. 184, 869-892. https://doi.org/10.1016/j.jclepro. 2018.02.267.

Jayakumar, K., Murugan, K., 2015. Solanum alkaloids and their pharmaceutical roles: a review. J. Anal. Pharm. Res. 3, 00075. https://doi.org/10.15406/japlr.2016.03. 00075.

Lang, Q., Wai, C., 2001. Supercritical fluid extraction in herbal and natural product studies-a practical review. Talanta 53, 771-782. https://doi.org/10.1016/S00399140(00)00557-9.

Leonardi, C., Giuffrida, F., 2009. Growth rate and carpometric characteristics during eggplant fruit growth. Acta Hortic. 807, 175-180. https://doi.org/10.17660/ ActaHortic.2009.807.21.

Li, H., Deng, Z., Zhu, H., Hu, C., Liu, R., Young, J.C., Tsao, R., 2012. Highly pigmented vegetables: anthocyanin compositions and their role in antioxidant activities. Food Res. Int. 46, 250-259. https://doi.org/10.1016/j.foodres.2011.12.014.

McGuire, R.G., 1992. Reporting of objective color measurements. HortScience 27, 1254-1255.

Mennella, G., Lo Scalzo, R., Fibiani, M., D’Alessandro, A., Francese, G., Toppino, L., Acciarri, N., De Almeida, A.E., Rotino, G.L., 2012. Chemical and bioactive quality traits during fruit ripening in eggplant (S. melongena L.) and allied species. J. Agric. Food Chem. 60, 11821-11831. https://doi.org/10.1021/jf3037424.

Mennella, G., Rotino, G.L., Fibiani, M., D’Alessandro, A., Franceses, G., Toppino, L., Cavallanti, F., Acciarri, N., Scalzo, R.L.O., 2010. Characterization of health-related compounds in eggplant (Solanum melongena L.) lines derived from introgression of allied species. J. Agric. Food Chem. 58, 7597-7603. https://doi.org/10.1021/ jf101004z.

Milner, S.E., Brunton, N.P., Jones, P.W., O Brien, N.M., Collins, S.G., Maguire, A.R., 2011. Bioactivities of glycoalkaloids and their aglycones from solanum species. J. Agric. Food Chem. 59, 3454-3484. https://doi.org/10.1021/jf200439q.

Niño-Medina, G., Urías-Orona, V., Muy-Rangel, M.D., Heredia, J.B., 2017. Structure and content of phenolics in eggplant (Solanum melongena) - a review. South African J. Bot. 111, 161-169. https://doi.org/10.1016/j.sajb.2017.03.016.

Noda, Y., Kneyuki, T., Igarashi, K., Mori, A., Packer, L., 2000. Antioxidant activity of nasunin, an anthocyanin in eggplant peels. Toxicology 148, 119-123. https://doi. org /10.1016/S0300-483X(00)00202-X.

Paul, A.T., Vir, S., Bhutani, K.K., 2008. Liquid chromatography-mass spectrometry-based quantification of steroidal glycoalkaloids from Solanum xanthocarpum and effect of different extraction methods on their content. J. Chromatogr. A 1208, 141-146. https://doi.org/10.1016/j.chroma.2008.08.089.

Peschel, W., Sánchez-Rabaneda, F., Diekmann, W., Plescher, A., Gartzía, I., Jiménez, D., Lamuela-Raventós, R., Buxaderas, S., Codina, C., 2006. An industrial approach in the search of natural antioxidants from vegetable and fruit wastes. Food Chem. 97, 137-150. https://doi.org/10.1016/j.foodchem.2005.03.033.

Prohens, J., Whitaker, B.D., Plazas, M., Vilanova, S., Hurtado, M., Blasco, M., Gramazio, P., Stommel, J.R., 2013. Genetic diversity in morphological characters and phenolic acids content resulting from an interspecific cross between eggplant, Solanum melongena, and its wild ancestor (S. incanum). Ann. Appl. Biol. 162, 242-257. https:// doi.org/10.1111/aab.12017.

Raigón, M.D., Rodríguez-Burruezo, A., Prohens, J., 2010. Effects of organic and conventional cultivation methods on composition of eggplant fruits. J. Agric. Food Chem. 58, 6833-6840. https://doi.org/10.1021/jf904438n.

Riggi, E., Avola, G., 2008. Fresh tomato packinghouses waste as high added-value biosource. Resour. Conserv. Recycl. 53, 96-106. https://doi.org/10.1016/j.resconrec. 2008.09.005.

Riggi, E., Avola, G., 2010. Quantification of the waste stream from fresh tomato packinghouses and its fluctuations: implications for waste management planning. Resour. Conserv. Recycl. 54, 436-441. https://doi.org/10.1016/j.resconrec.2009.09.008.

Schieber, A., Stintzing, F., Carle, R., 2001. By-products of plant food processing as a source of functional compounds - recent developments. Trends Food Sci. Technol. 12, 401-413. https://doi.org/10.1016/S0924-2244(02)00012-2.

Steyn, W.J., Wand, S.J.E., Holcroft, D.M., Jacobs, G., 2002. Anthocyanins in vegetative tissues: a proposed unified function in photoprotection. New Phytol. 155, 349-361. https://doi.org/10.1046/j.1469-8137.2002.00482.x.

Stommel, J.R., Whitaker, B.D., 2003. Phenolic acid content and composition of eggplant fruit in a germplasm core subset. J. Am. Soc. Hort. Sci. 128, 704-710. https://doi. org $/ 10.1002 / \mathrm{mnfr} .200600067$.

Todaro, A., Cimino, F., Rapisarda, P., Catalano, A.E., Barbagallo, R.N., Spagna, G., 2009. Recovery of anthocyanins from eggplant peel. Food Chem. 114, 434-439. https:// doi.org/10.1016/j.foodchem.2008.09.102.

Toppino, L., Barchi, L., Lo Scalzo, R., Palazzolo, E., Francese, G., Fibiani, M., D'Alessandro, A., Papa, V., Laudicina, V.A., Sabatino, L., Pulcini, L., Sala, T., Acciarri, N., Portis, E., Lanteri, S., Mennella, G., Rotino, G.L., 2016. Mapping quantitative trait 
loci affecting biochemical and morphological fruit properties in eggplant (Solanum melongena L.). Front. Plant Sci. 7, 1-16. https://doi.org/10.3389/fpls.2016.00256. Whitaker, B.D., Stommel, J.R., 2003. Distribution of hydroxycinnamic acid conjugates in fruit of commercial eggplant (Solanum melongena L.) cultivars. J. Agric. Food Chem. 51, 3448-3454. https://doi.org/10.1021/jf026250b.

Xu, C., Shi, W., Hong, J., Zhang, F., Chen, W., 2015. Life cycle assessment of food wastebased biogas generation. Renew. Sustain. Energy Rev. 49, 169-177. https://doi.org/ 10.1016/j.rser.2015.04.164.
Zaro, M.J., Chaves, A.R., Vicente, A.R., Concellón, A., 2014. Distribution, stability and fate of phenolic compounds in white and purple eggplants (Solanum melongena L.). Postharvest Biol. Technol. 92, 70-78. https://doi.org/10.1016/j.postharvbio.2014. 01.016.

Zaro, M.J., Vicente, A.R., Ortiz, C.M., Chaves, A.R., Concellón, A., 2015. Eggplant. In: Hui, Y.H., Evranuz, E.Ö. (Eds.), Handbook of Vegetable Preservation and Processing. CRC Press, Boca Raton, pp. 479-493. 